\title{
The continuing saga of aging and heart failure
}

\author{
Bodh I. Jugdutt
}

Published online: 19 January 2012

(C) Springer Science+Business Media, LLC 2012

As the American pop singers Sonny and Cher put it, "the beat goes on..." The first special symposium issue of Heart Failure Reviews on Aging and Heart Failure (HF) was published in September 2010. It drew attention to the arbitrary chronological definition of the elderly and the importance of the changing demographics with respect to the growing population of elderly people with major aging-related cardiovascular (CV) diseases that lead to HF, such as hypertension and myocardial infarction [1]. In that issue, a group of clinicianscientists discussed pertinent aspects of epidemiology and management of elderly patients with STEMI and HF [2, 3]. Other expert clinician-scientists addressed, in the context of aging and HF, the role of inflammatory implications and fibrogenic pathways [4], autophagy [5], sarcoplasmic reticulum calcium signaling [6], stem cells [7], adiponectin [8], resveratrol and longevity [9], telomeres [10], osteopontin [11] and beta-adrenergic signaling [12].

As guest editor of the first issue, I emphasized the importance of understanding the biology of cardiovascular aging and its impact on the pathophysiology of HF. I pointed out that recognizing that the aging process is associated with physiological as well as biochemical, molecular, cellular and extracellular changes is critical for development and discovery of novel targets and therapies pertinent to that growing segment of the population. In September 2010, I had the opportunity to drive those points home at a lecture on "The biology of aging in the cardiac patient" for a new symposium on "Biology of Aging and HF Management" during the 14th Annual scientific meeting of the HF Society

\section{B. I. Jugdutt $(\square)$}

Department of Medicine, Division of Cardiology, University

of Alberta and Hospitals, 2C2 Walter MacKenzie Health

Sciences Centre, Edmonton, AB T6G 2R7, Canada

e-mail: bjugdutt@ualberta.ca of North America in San Diego. In October 2011, the chair person of my session asked me whether we should define elderly as age $\geq 65$ years after a talk dealing with chronological versus biological aging and HF in the elderly, indicating the continuing need for increased awareness. At the 20th Annual Meeting of the American Heart Association in Orlando, November 2011, it was gratifying to see that a last day afternoon session (2-5 pm) entitled "Aging, death and CV homeostasis" should attract an audience of predominantly young researchers.

HF remains an important problem in the elderly in North America, Europe and other developed countries. Improved medicine, public health, Medicare and socioeconomic conditions in Western countries have extended life span. However, this increased longevity is sadly associated with a parallel increase in morbidity due to HF. There is an increasing need for development and discovery of novel targets and therapies pertinent to the growing elderly population in order to ensure that they enjoy the extended life span and continue to contribute meaningfully to society if they so choose. Since the changes with aging are progressive and a host of risk factors damage the CV system during aging, improving the lot of the older, elderly and oldest elderly segments depends to some extent on the success of preventative measures in the young, beginning in early childhood.

The beat must go on. This second Symposium issue of Heart Failure Reviews includes a series of 15 review articles focused on aging-related issues pertinent to HF in the elderly. The first twelve papers deal with clinical issues. In the lead article, I address HF prevention strategies in the context of the aging continuum and chronological versus biological aging, and discuss promotion of healthy aging through education on $\mathrm{CV}$ risk factors and prevention through aggressive $\mathrm{CV}$ risk management. Jerome Fleg addresses the role of aging-related changes in $\mathrm{CV}$ structure 
and function in the development of CV disease. Ken Kaila and associates in Ian Paterson's group address aging-related diastolic dysfunction and HF with preserved ejection fraction (HF-PEF). Jonathan Man and I discuss issues with optimizing management of systolic HF or HF with low ejection fraction (HF-low EF) in the elderly and the need for clinical trial data on all elderly population segments. Bertram Pitt discusses the utility of mineralocorticoid receptor antagonists (MRAs) in a very old patient, in whom the age-related decrease in aldosterone levels is balanced by a novel pathway involving decreased $11 \beta$ HSD-2 levels and cortisol-induced stimulation of the mineralocorticoid receptor. Khalid Murad and Dalane Kitzman discuss the implications of frailty and multiple comorbidities in $\mathrm{HF}$ management of an elderly patient. Michael Rich discusses adverse drug events with HF pharmacotherapy in the elderly. Pedram Kazemian, Gavin Oudit and I discuss causes and current management issues with atrial fibrillation in elderly HF patients, and the need for trial data on the older and oldest elderly patients. Craig Butler and I discuss issues surrounding mechanical circulatory support in elderly end-stage HF patients. Tissa Kappagoda and Ezra Amsterdam address the physiological responses to exercise in the elderly and emphasize the benefits of exercise training. Craig Butler and I discuss the potential use of the left ventricular assist device (LVAD) for destination therapy versus bridge to recovery (BTR) in the older adult and elderly patients with end-stage HF, and the paradoxical finding of reverse remodeling with insufficient functional recovery to qualify for BTR.

Also in this issue, four papers deal with some important translational research areas. Naranjan Dhalla and colleagues discuss the role of subcellular remodeling of calcium handling and binding proteins in HF due to myocardial infarction and aging. Gavin Oudit and associates discuss the role of ACE-2 in diastolic and systolic HF. Zamaneh Kassiri and associates discuss the role of tissue inhibitor of metalloproteinases (TIMPs) in HF. Finally, Miranda Sung and Jason Dyck discuss the beneficial effects of calorie restriction and resveratrol in age-related $\mathrm{CV}$ disease.

These articles provide the healthcare professionals including physicians and clinician-scientists, fellows, trainees and students with a valuable resource on pertinent aspects of age-related changes in physiology, biochemistry and pathophysiology that impact HF management in the elderly and important clinical issues in the care of the elderly HF patient. The reviews should give the readers an appreciation of the need for more research on the biology of $\mathrm{CV}$ aging, more evidence-based clinical trial data on the "older-elderly" HF patients and the need for new therapies for HF-PEF as well as for HF-low EF. Together, they point out that while longer life comes at a price, there is still hope and potential for novel targets and therapies in the near future.

Conflict of interest None.

\section{References}

1. Jugdutt BI (2010) Aging and heart failure: changing demographics and implications for therapy in the elderly. Heart Fail Rev 15:401-405

2. Ezekowitz JA, Kaul P (2010) The epidemiology and management of elderly patients with myocardial infarction or heart failure. Heart Fail Rev 15:407-413

3. Jelani A, Jugdutt BI (2010) STEMI and heart failure in the elderly: role of adverse remodeling. Heart Fail Rev 15:513-521

4. Chen W, Frangogiannis NG (2010) The role of inflammatory and fibrogenic pathways in heart failure associated with aging. Heart Fail Rev 15:415-422

5. De Meyer GR, De Keulenaer GW, Martinet W (2010) Role of autophagy in heart failure associated with aging. Heart Fail Rev $15: 423-430$

6. Janczewski AM, Lakatta EG (2010) Modulation of sarcoplasmic reticulum $\mathrm{Ca}(2+)$ cycling in systolic and diastolic heart failure associated with aging. Heart Fail Rev 15:431-445

7. Ballard VLT (2010) Stem cells for heart failure in the aging heart. Heart Fail Rev 15:447-456

8. Shinmura K (2010) Is adiponectin a bystander or a mediator in heart failure? The tangled thread of a good-natured adipokine in aging and cardiovascular disease. Heart Fail Rev 15:457-466

9. Das DK, Mukherjee S, Ray D (2010) Resveratrol and red wine, healthy heart and longevity. Heart Fail Rev 15:467-477

10. Wong LS, van der Harst P, de Boer RA, Huzen J, van Gilst WH, van Veldhuisen DJ (2010) Aging, telomeres and heart failure. Heart Fail Rev 15:479-486

11. Singh M, Foster CR, Dalal S, Singh K (2010) Role of osteopontin in heart failure associated with aging. Heart Fail Rev 15:487-494

12. Ho D, Yan L, Iwatsubo K, Vatner DE, Vatner SF (2010) Modulation of beta-adrenergic receptor signaling in heart failure and longevity: targeting adenylyl cyclase type 5. Heart Fail Rev 15: 495-512 